MEETING REPORT

\section{Lisbon provides Port in a storm for WMSM}

Torrential rain and thunderstorms did nothing to dampen the mood at the World Meeting on Sexual Medicine (WMSM), which was held in Lisbon, Portugal, between 28 February and 3 March 2018. This combined meeting comprised the 21st World Meeting of the International Society for Sexual Medicine (ISSM) and the 20th Congress of the European Society for Sexual Medicine (ESSM).

In a meeting full of highlights, a Keynote Lecture by Tim Urban, of Wait but Why, offered his insights into the future of sexual medicine in his own inimitable style. A varied programme of workshops, poster presentations, and symposia illustrated the wide variety of topics covered by the field of sexual medicine, from basic research to psychology. Nature Reviews Urology presented poster prizes for the third consecutive ESSM congress, and, for the first time, a prize was presented for the best psychosexual research, emphasizing the growing importance of a holistic approach to sexual medicine.

The workshops were identified as particular highlights by the participants and the organisers. "The workshops at this year's congress were a great success," comments Educational Committee Chairman Mikkel Fode. "The rooms were packed with people standing in line at the door and even sitting on the floors. I really believe people came away with new insights." Incoming ESSM President Cobi Reisman also comments on the applicability of the workshops to attendees' clinical practice: "For participants, it was possible to gather knowledge from basic and clinical science that is applicable to daily sexual medicine healthcare."

Notably, the meeting also hosted the first symposium of the Young Sexual Medicine Academy. This committee, under the ESSM umbrella, is committed to supporting the younger members of the society and ensuring a positive future for sexual medicine.

The next World Meeting on Sexual Medicine will be held in Yokohama, Japan, in 2020, preceded by the 2019 ESSM Congress in Ljubljana, Slovenia.

Annette Fenner 